\title{
PHAGODETERRENT ACTIVITY OF PROSOPIS SPICIGERA FOLIAR EXTRACT AGAINST CALLOSOBRUCHUS CHINENSIS (L.)
}

\author{
P. C. BHATI \\ Department of Zoology, Government P. G. College, Bundi (Rajasthan)
}

\begin{abstract}
Acetone extract of leaves of Prosopis spicegera was evaluated for its phagodeterrent properties against the pulse beetle, Callosobruchus chinensis. At $100 \%$ dose level, average oviposition, average emergence, percent seed protection and percent seed protection over control were found to be 145.66, 52, 47.32 and 14.977, respectively.
\end{abstract}

Key words : Phagodeterrent, Callosobruchus chinensis, Prosopis spicigera.

\section{INTRODUCTION}

One of the factors leading to the development of human settlements and the civilization has been the advances in the field of agriculture and methods of storage of food grains. Apart from the purpose of consumption in future the food grains are also stored as seeds for sowing purposes in the next season. Despite being the foundation of civilization and even the existence of mankind in present era, agriculture and warehouses face the age old threat posed by the pests. Insect pests alone have been claiming a considerable part of annual agricultural produce during both harvesting and post-harvesting phases.

Before advent of new synthetic chemical pesticides, farmers had tried the naturally occurring substances for the pest management. They applied their knowledge of natural pesticidal and repellent properties of certain plant species such as Neem and tried them to protect their agricultural produce. However, discovery of synthetic chemical pesticides such as DDT with promising results attracted the farmers across the globe. These pesticides were initially considered the savior for agriculture and helped get rid of the menace of pests to certain extent. But their side effects on the environment and biodiversity are so drastic that these are banned in many developed nations.

Keeping in mind the adverse effects of the synthetic chemical pesticides, scientists all over the world have been working on the eco-friendly alternatives for the pest management. Further, plant products are being explored for the safer approach to the pest management. Present work also deals with the assessment of the phagodeterrent activity of foliar extract of P.spicigera against pulse beetle, C.chinensis.

\section{MATERIAL AND METHODS}

Rearing of experimental insect : In laboratory, culture of Callosobruchus chinensis was maintained in pre-sterilized jars containing disinfested cowpea seeds. The optimum condition of $27 \pm 2^{\circ} \mathrm{C}$ temperature and $60 \pm 10$ percent relative humidity was maintained. Freshly emerged adults (0-24 hrs.) were taken for experimentation.
Collection and extraction of plant materials : Leaves of Prosopis spicigera were thoroughly washed with water to remove the dust and dirt particles. Further, they were dried in shade and powdered separately with the help of an electric grinder. The extracts were prepared separately by soxhlet extraction method (Deshmukh and Borle, 1975) using acetone as solvent. $30 \mathrm{gm}$ of powder was extracted with $300 \mathrm{ml}$ of acetone keeping the ratio $1: 10$. The duration of extraction process was kept eight hours. After filtration, the extract was kept in refrigerator as stock solution.

Experimental design : 5 gm of cowpea seeds were taken in plastic vials and treated with $1 \mathrm{ml}$ of each desired dose level, i.e. 25, 50, 75 and 100 of the acetone extract of Prosopis spicigera leaves. The doses were prepared by mixing the extracts with respective volume of the solvent. Three replicas of each dose level and a control containing seeds treated with the solvent (acetone) only were run parallel. Three pairs of newly emerged adult (0-24 hrs. old) were introduced in each vial for egg laying on the grains. The vials were covered with muslin cloth. The number of eggs laid on seeds and the number of adults emerged were recorded. The loss in seed weight was calculated by weighing the damaged seeds separately.

\section{RESULTS AND DISCUSSION}

Table. 1 depicts the results of phagodeterrent properties of the foliar extract of Prosopis spicigera against pulse beetle, Callosobruchus chinensis. The results show that the oviposition potential of the beetle declined gradually with ascending concentration of the extract since 186.33, 175.33, 157.66 and 145.66 eggs were counted at $25 \%, 50 \%, 75 \%$ and $100 \%$ dose levels, respectively while the maximum oviposition (206) was depicted by the control. Average adult emergence was also found to be dose dependent as it decreased with an increase in dose level hence at $25 \%, 50 \%$, $75 \%$ and $100 \%$ dose levels the average adult emergence recorded was $60.66,56.33,55.33$ and 52 , respectively as compared to 73 adults counted in the control. At 25\%, 50\%, 75\% and $100 \%$ dose levels average loss in seed weight recorded were $2.970,2.861,2.768$ and 2.634 grams, respectively while in control maximum loss in seed weight (3.098 grams) was observed. Percent seed protection validated was 40.6, 42.78, 
Table. 1 Phagodeterrent action of foliar extract of Prosopis spicigera against Callosobruchus chinensis.

\begin{tabular}{|c|c|c|c|c|c|c|c|c|}
\hline S. & $\begin{array}{l}\text { Dose } \\
\text { level }\end{array}$ & $\begin{array}{c}\text { Average } \\
\text { oviposition }\end{array}$ & $\begin{array}{c}\text { Average } \\
\text { emergence }\end{array}$ & $\begin{array}{l}\text { Percent adult } \\
\text { emergence }\end{array}$ & $\begin{array}{l}\text { Average loss in } \\
\text { seed weight (gm) }\end{array}$ & $\begin{array}{c}\text { Average seed } \\
\text { protection }(\mathrm{gm})\end{array}$ & $\begin{array}{c}\text { Percent seed } \\
\text { protection }\end{array}$ & $\begin{array}{l}\% \text { seed protection } \\
\text { over control }\end{array}$ \\
\hline 1. & $25 \%$ & 186.33 & 60.66 & 32.55 & 2.970 & 2.030 & 40.60 & 4.131 \\
\hline 2. & $50 \%$ & 175.33 & 56.33 & 32.12 & 2.861 & 2.139 & 42.78 & 7.650 \\
\hline 3. & $75 \%$ & 157.66 & 55.33 & 35.09 & 2.768 & 2.232 & 44.64 & 10.652 \\
\hline 4. & $100 \%$ & 145.66 & 52 & 35.69 & 2.634 & 2.366 & 47.32 & 14.977 \\
\hline 5. & Control & 206 & 73 & 35.43 & 3.098 & 1.902 & 38.04 & - \\
\hline
\end{tabular}

Number of replications - 3

Weight of treated cowpea seeds in each replication - 5 grams

Number of adults in each replication - 6 (3 males +3 females $)$

44.64 and 47.32 at $25 \%, 50 \%, 75 \%$ and $100 \%$ dose levels, respectively while only $38.04 \%$ seed protection was recorded in control. Percent seed protection over control calculated at $100 \%$ dose levels was 14.977 .

Tembo et al. (2018), Roy et al. (2016), Talukder \& Howse (1994), Su (1990), Bhaduri et al. (1985) and Babu et al. (1989) also assessed potential of various plant extracts against pests which supports present findings. Bhati (2017) in another study found that Nyctanthes arbortristis has $85.078 \%$ seed protection over control for $100 \%$ dose level. The moderate antifeedent action shows that P.spicigera, despite having some phagodeterrent properties, is not a promising alternative for the management of the stored grain pest, pulse beetle.

\section{REFERENCES}

Babu, T. R.; Reddy, V. S. and Hussaini, S. H. (1989). Effect of edible and non-edible oils on the development of pulse beetle (Callosobruchus chinensis L.) and on viability and yield of mungbean (Vigna radiata). Tropical Science, 29:215-220.

Bhaduri, N.; Ram, S. and Patil, B. D. (1985). Evaluation of some plant extracts as protectants against the pulse beetle, Callosobruchus maculatus (F.) infesting cowpea seed. J. Entomol. Res., 9(2) :183-187.

Bhati, P. C. (2017). Evaluation of phagodeterrent action of Nyctanthes arbor-tristis seed extract against Callosobruchus chinensis (L.). Life Science Bulletin, 14(2) : 245-246.

Deshmukh, S. D. and Borle, M. N. (1975). Studies on insecticidal properties of indigenous plant products. Ind. J. Ent., 35(1) : $111-118$.

Roy, S.; Handique, G.; Muraleedharan, N.; Dashora, K.; Roy, S. M.; Mukhopadhyay, A. and Babu, A. (2016). Use of plant extracts for tea pest management in India. Appl. Microbiol Biotechnol., $100: 4831-4844$.

Su, H. C. F. (1990). Biological activities of hexane extract of Piper cubeba against rice weevils and cowpea weevils. J. Entomol. Sci., 25(1) : 16-20.

Talukder, F. A. and Howse, P. E. (1994). Repellent toxic and food protectant effects of Aphanamixis polystachya extract against pulse beetle, Callosobruchus chinensis in storage.J. Chem. Ecol., 20(4) : 899-908.

Tembo, Y.; Mkindi, A. G.; Mkenda, P. A.; Mpumi, N.; Mwanauta, R.; Stevenson, P. C.; Ndakidemi, P. A. and Belmain, S. R. (2018). Pesticidal plant extracts improve yield and reduce insect pests on legume crops without harming beneficial arthropods. Frontiers in Plant Science, 9: 1425 . 